\title{
Effect of the cooling rate on microstructure and hardness of MAR-M247 Ni-based superalloy
}

\author{
Srdjan Milenkovic ${ }^{\mathrm{a}, *}$, Ilchat Sabirov ${ }^{\mathrm{a}}$, Javier LLorca ${ }^{\mathrm{a}, \mathrm{b}}$
}

\begin{abstract}
A B S T R A C T
The effect of cooling rate on the microstructure of MAR-M247 Ni-based superalloy was investigated via physical simulation of the casting process. Solidification experiments with cooling rates in the range of $0.25-10 \mathrm{~K} / \mathrm{s}$ showed smooth temperature profiles with measured cooling rates matching the set values. The MAR-M247 showed cellular $(0.25 \mathrm{~K} / \mathrm{s})$ and dendritic $(1,5$ and $10 \mathrm{~K} / \mathrm{s})$ microstructures. Microconstituents also varied with cooling rates: $\gamma / \gamma^{\prime}$ matrix with carbides and $\gamma / \gamma^{\prime}$ eutectic at $0.25 \mathrm{~K} / \mathrm{s}, \gamma / \gamma^{\prime}$ matrix with carbides at $1 \mathrm{~K} / \mathrm{s}$, and $\gamma / \gamma^{\prime}$ matrix with carbides and $\gamma / \mathrm{MC}$ eutectic at 5 and $10 \mathrm{~K} / \mathrm{s}$. Moreover, the secondary dendritic arm spacing decreased and the hardness increased with the increase in the cooling rates.
\end{abstract}

\section{Introduction}

Over the last three decades, significant progress has been made in the development of cast Ni-based superalloys as well as in the casting technology to obtain tailored microstructures. Among the various cast alloys, MAR-M247 has been widely used for high temperature applications in turbine rotor blisks and stators. It is a Ni-based, vacuum melted, cast superalloy with high volume fraction of $\gamma^{\prime} \mathrm{Ni}_{3}(\mathrm{Al}, \mathrm{Ti})(\approx 62 \%)$ and high $(\mathrm{Ta}+\mathrm{W}+\mathrm{Mo})$ refractory element content (14 wt.\%) [1]. The alloy was developed in the early 1970 s by Danasi et al. at Martin Metals Corporation [1] and presents good castability, exceptional high temperature strength, corrosion and oxidation resistance. It is commonly produced by directional solidification to improve creep rupture strength.

Most fundamental studies on the microstructural evolution of MARM247 alloy are related to directional solidification [2-6], while studies focused on conventional and investment casting processes are very limited [7]. The present work aims at covering this gap by investigating the effect of cooling rate on the microstructure of MAR-M247 Ni-based superalloy via physical simulation of the casting process. It has been shown that the dendrite spacing during directional solidification could be correlated with the cooling rate $R$ in various Ni-based alloys, including MAR-M247 [2]. The same authors [4] have demonstrated that the microporosity depends on the hydrogen content and growth parameter, and that there is an optimum withdrawal velocity which leads to a minimum porosity and closely spaced dendrite arms. Moreover, Chen et al. [3] reported that the carbide volume fraction and average size increased with increasing the growth rate. Nathal et al. [5,7] on the other hand, investigated the influence of chemical composition on the microstructure evolution. In the investment cast alloy, the $\gamma^{\prime}$ volume fraction and the mean particle size increased, while the amount of carbides present decreased with Co content [7]. In the single crystal alloy, substitution of $\mathrm{Ni}$ for Co caused an increase in $\gamma^{\prime}$ solvus temperature and in $\gamma-\gamma^{\prime}$ lattice mismatch, as well as the precipitation of W-rich phases. On the other hand, substituting Ni for Ta led to large reduction in $\gamma^{\prime}$ solvus temperature, $\gamma^{\prime}$ volume fraction, and $\gamma-\gamma^{\prime}$ lattice mismatch [5].

It should be finally noted that physical simulation has not been widely used to study the casting of Ni-based superalloys. Heck [8] studied the castability of directionally-solidified IN792 and CM247LC, while Robino [9] investigated the solidification and welding metallurgy of thermospan alloy. In addition, Sekhar et al. $[10,11]$ reported the solidification morphology and semisolid deformation in both equiaxed and directionally-solidified RENE-108 superalloy. Finally, Knorovsky et al. [12] used Gleeble simulation along with DTA analysis to develop the solidification diagram of IN 718 alloy. However, there is no information available in the open literature on the physical simulation of casting of MAR-M247.

In this article, a detailed study on the effect of cooling rate on the microstructure during casting is carried out via physical simulation route. The variation of microconstituents and dendritic arm spacing is compared and is correlated with the hardness.

\section{Materials and methods}

The material used in this investigation was a MAR-M247 superalloy of chemical composition (wt.\%): $\mathrm{C}=0.15, \mathrm{Cr}=8.0, \mathrm{Mo}=0.6, \mathrm{Ti}=1.0$, $\mathrm{Co}=10.0, \mathrm{~W}=10.0, \mathrm{Ta}=3.0, \mathrm{Al}=5.5, \mathrm{Hf}=1.5, \mathrm{~B}=0.015, \mathrm{Zr}=0.03$ 


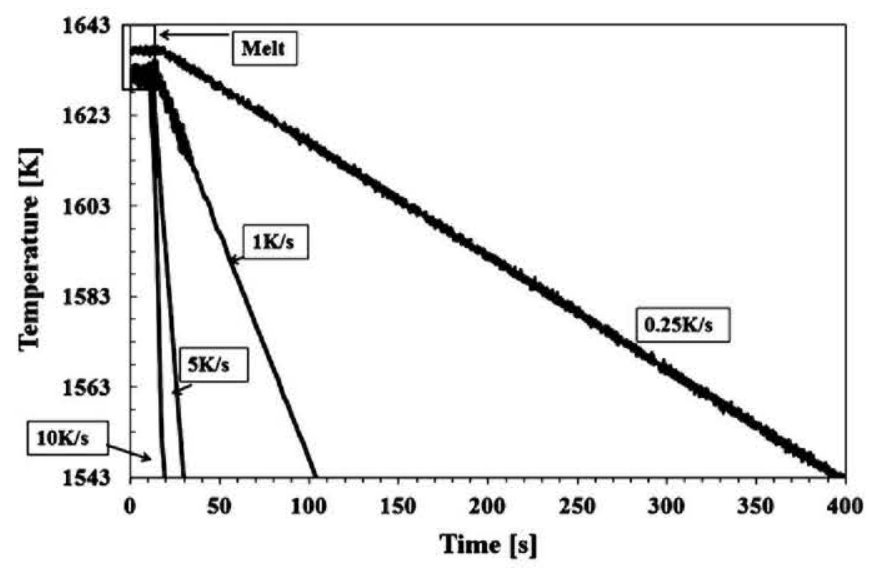

Fig. 1. Temperature vs. time curves recorded during solidification experiments.

and $\mathrm{Ni}=$ bal, supplied by Precicast Bilbao. Specimens with diameter of $10 \mathrm{~mm}$ and $121.5 \mathrm{~mm}$ in length were machined from larger ingots. A thin wire thermocouple ( $R$-type) was welded to the midsection of each specimen to control the temperature during the solidification experiment. The liquid metal zone was contained in a quartz tube with a slot of $3.2 \mathrm{~mm}$, which was put onto each specimen with the thermocouple in the slot. Thermocouple wires were fixed to the surface of the quartz tube by cement. Melting/solidification experiments were performed in the argon atmosphere using a GLEEBLE 3800 system for physical simulation.

MAR-M247 samples were heated at a rate of $40 \mathrm{~K} / \mathrm{s}$ to $1513 \mathrm{~K}$ $\left(1240^{\circ} \mathrm{C}\right)$. In the temperature range of $1513-1593 \mathrm{~K}$, the heating rate was reduced to $2 \mathrm{~K} / \mathrm{s}$. When $1593 \mathrm{~K}$ is reached, the temperature was manually increased very slowly up to $\sim 1633 \mathrm{~K}$ until an evidence of melting was observed. The specimen was held at this temperature for $10 \mathrm{~s}$ and thereafter cooled down by $100 \mathrm{~K}$ at four different cooling rates, $0.25,1,5$, and $10 \mathrm{~K} / \mathrm{s}$. These cooling rates were carefully chosen and correspond to the expected cooling rates in different parts of the mold during investment casting of MAR-M247 to manufacture nozzle guide vanes [13]. The experimental cooling rate was estimated as a slope of the temperature-time curve corresponding to the solidification stage. The samples were compressed in a stroke controlled manner to suppress formation of shrinkage porosity. Microhardness of the material was measured using SHIMADZU HMV-2 microhardness tester equipped with Vickers diamond indenter. The load of $300 \mathrm{~g}$ was applied for $15 \mathrm{~s}$. Ten measurements were carried out in each sample.

A midsection of the melted zone was cut out for further microstructural studies. They were polished to the mirror-like surface finish using colloidal silica at the final stage and etched using Glyceregia $(15 \mathrm{ml} \mathrm{HCl}$, $10 \mathrm{ml}$ glycerol and $5 \mathrm{ml} \mathrm{HNO}_{3}$ ). The microstructure formed during solidification in the temperature-controlled area (the area under the weld point of thermocouple) was studied in scanning electron microscope EVO MA 15 at an operating voltage of $18 \mathrm{kV}$.

\section{Results and discussion}

The temperature-time plots for different cooling rates are presented in Fig. 1. They show that the cooling rate was very well controlled at cooling rates of $0.25,1$, and $5 \mathrm{~K} / \mathrm{s}$. Some instabilities appeared at the highest cooling rate of $10 \mathrm{~K} / \mathrm{s}$, but this did not affect the average cooling rate. So, the experimental average cooling rates matched the set ones (Table 1). This indicates that the casting process with precisely controlled cooling rates can be successfully reproduced in the Gleeble thermomechanical simulator.

The cooling rate, $R[\mathrm{~K} / \mathrm{s}]$, is a product of the temperature gradient, $G$ $[\mathrm{K} / \mathrm{mm}]$ and the solidification rate, $\mathrm{V}[\mathrm{mm} / \mathrm{s}]$. In order to estimate the solidification rate, additional experiments were carried out, in which the temperature gradients were measured. Two R-type thermocouples were welded to the surface of cylindrical specimens. One thermocouple was welded to the midsection and the other $4 \mathrm{~mm}$ aside. Temperature gradients, defined as the temperature difference measured by these thermocouples divided by the distance between thermocouples, were calculated from the temperature-time plots recorded by the thermocouples. As indicated in Table 1 , they were $\sim 1 \mathrm{~K} / \mathrm{mm}$ for the cooling rates of 0.25 and $1 \mathrm{~K} / \mathrm{s}$ and increased to $\sim 5 \mathrm{~K} / \mathrm{mm}$ for the cooling rates of 5 and $10 \mathrm{~K} / \mathrm{s}$. The difference is due to the geometrical variations of the copper grips used to hold the sample. For low cooling rates, partial contact copper grips were used with a contact length with the specimen of $12 \mathrm{~mm}$, while full contact copper grips with a contact length with the specimen of $30.5 \mathrm{~mm}$ were used for high cooling rates. Hence, the solidification rates in the midsection of samples were calculated to be $0.25,1$, 1 and $2 \mathrm{~mm} / \mathrm{s}$, respectively (Table 1 ).

The initial microstructure of the MAR-M247 alloy consisted of $\gamma \mathrm{Ni}$ rich solid solution containing a dispersion of $\gamma^{\prime}$ precipitates, discrete metal carbide (MC) particles, and $\gamma / \gamma^{\prime}$ eutectic pools as depicted in Fig. 2a. After solidification, the microstructure varied with the cooling rate. Common observation was the absence of pores, except from central shrinkage, whose size decreased with the solidification rate.

The sample cooled at $0.25 \mathrm{~K} / \mathrm{s}$ showed cellular morphology with the same microstructural constituents as the as-cast sample: $\gamma / \gamma^{\prime}$ matrix, metal carbides and $\gamma / \gamma^{\prime}$ eutectic (Fig. 2b). The sample solidified at a cooling rate of $1 \mathrm{~K} / \mathrm{s}$ showed an obvious transition from cellular to dendritic growth (Fig. 2c). The dendritic structure was well defined through formation of the secondary arms. These secondary dendrites result from capillary instabilities at the dendrite tip. These perturbations are small at first and then grow at the expense of the smaller arms in a process similar to Ostwald ripening. The driving force for this coarsening is the increase in interfacial energy at the tips of the smaller arms due to the higher curvature there [14]. The microstructure comprised only $\gamma / \gamma^{\prime}$ matrix and carbides, without the presence of $\gamma / \gamma^{\prime}$ eutectic. Microstructure of the samples solidified at 5 and $10 \mathrm{~K} / \mathrm{s}$ was similar and contained primary dendrites, carbides and $\gamma / \mathrm{MC}$ eutectic pools resulting from the reaction $\mathrm{L} \rightarrow \gamma+\mathrm{MC}$ in which liquid transforms into two solid phases, $\gamma$ and MC (Fig. 2d). The presence of the eutectic microstructure indicates that the undercooling of the last to solidify liquid and its composition fulfilled the conditions for eutectic solidification inside the coupled-growth zone (CGZ). CGZ is defined as a range of alloy composition and interface temperature (or velocity) where eutectic growth prevails upon solidification [15-17]. The observed microconstituents are summarized in Table 1 as a function of the cooling rate. The samples cooled at 1 and $5 \mathrm{~K} / \mathrm{s}$ yielded the same solidification rate but differed in microstructure. This behavior was due to the differences in thermal gradient which affects the dendrite spacing and the microstructure evolution in the same manner as the solidification rate. The

Table 1

Nominal and measured cooling rates and their influence on the temperature gradient, solidification rate, microconstituents and microhardness of MAR-M247 alloy.

\begin{tabular}{|c|c|c|c|c|c|}
\hline \multicolumn{2}{|c|}{ Cooling rate, $R[\mathrm{~K} / \mathrm{s}]$} & \multirow{2}{*}{$\begin{array}{l}\text { Temperature gradient, } \\
G[\mathrm{~K} / \mathrm{mm}]\end{array}$} & \multirow{2}{*}{$\begin{array}{l}\text { Solidification rate, } \\
V[\mathrm{~mm} / \mathrm{s}]\end{array}$} & \multirow[t]{2}{*}{ Constituent phases } & \multirow[t]{2}{*}{ Hardness } \\
\hline Set & Measured & & & & \\
\hline 0.25 & 0.250 & 1 & 0.25 & $\gamma / \gamma^{\prime}+\mathrm{MC}+\gamma / \gamma^{\prime}$ eutectic & 403.2 \\
\hline 1.00 & 1.001 & 1 & 1 & $\gamma / \gamma^{\prime}+\mathrm{MC}$ & 432.0 \\
\hline 5.00 & 5.026 & 5 & 1 & $\gamma / \gamma^{\prime}+\mathrm{MC}+\gamma / \mathrm{MC}$ eutectic & 447.0 \\
\hline 10.00 & 11.285 & 5 & 2 & $\gamma / \gamma^{\prime}+\mathrm{MC}+\gamma / \mathrm{MC}$ eutectic & 449.2 \\
\hline
\end{tabular}




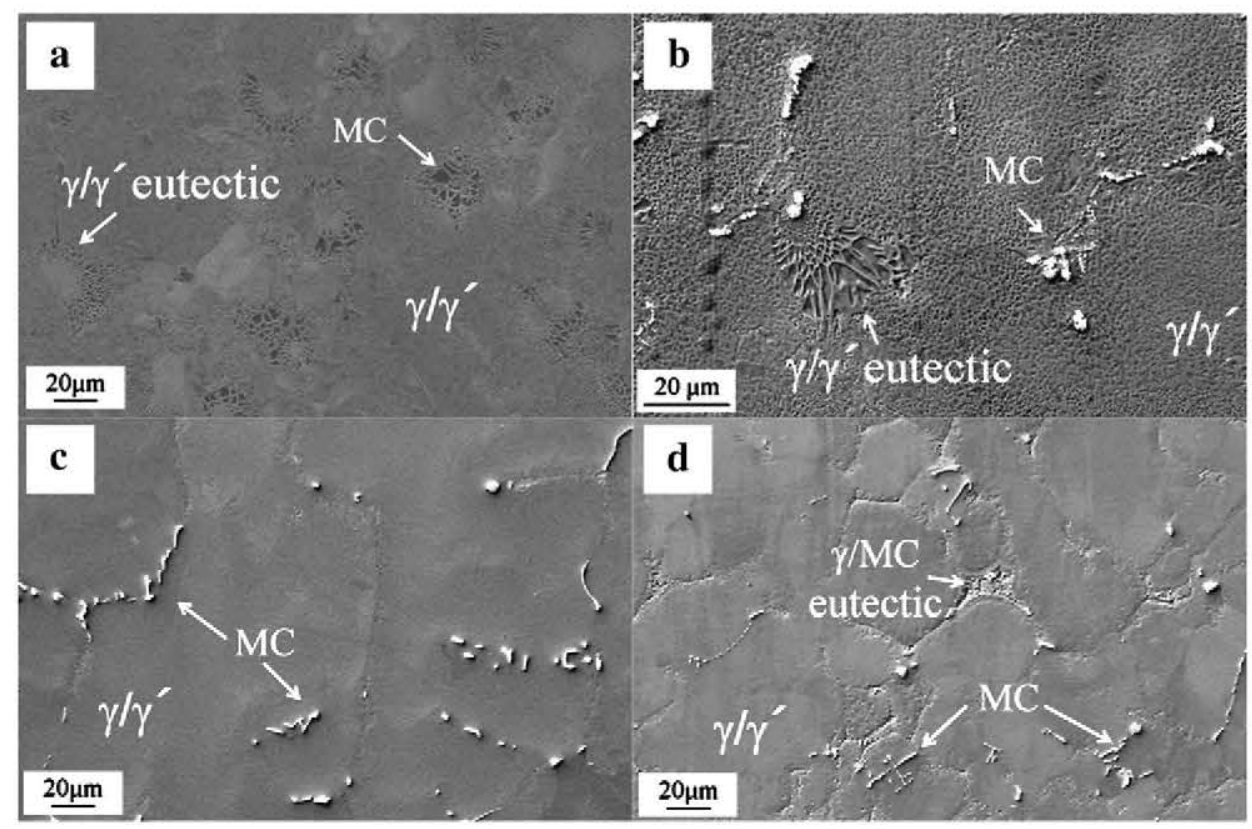

Fig. 2. Typical microstructures of the MAR-M247 alloy: a) as cast and cooled at b) $0.25 \mathrm{~K} / \mathrm{s}$; c) $1 \mathrm{~K} / \mathrm{s}$, and d) 5 and $10 \mathrm{~K} / \mathrm{s}$.

sample solidified at higher temperature gradient underwent higher undercooling resulting in different microconstituents.

In the samples with dendritic structure (samples cooled at 1,5 and $10 \mathrm{~K} / \mathrm{s}$ ), secondary dendrite arm spacing was measured by counting the number of secondary arms over a measured length on a minimum of five well aligned dendrite trunks. The results are shown in Fig. 3. It can be seen that the secondary arm spacing decreased as the cooling rate increased according to the following relation:

$\lambda=K R^{n}$

where, $\lambda$ is the secondary arm spacing, $K$ and $n$ are material constants, and $R$ is the cooling rate. $K=1.54$ and $n \approx 0.3$ were obtained by the least square fitting of the experimental data and they were in good agreement with the theory [15].

In addition, the influence of the microstructure on the microhardness is depicted in Fig. 3. The Vickers hardness increased from 403.2 to 449.2 as the cooling rate increased from 0.25 to $10 \mathrm{~K} / \mathrm{s}$. This variation in hardness values was mainly controlled by the morphology and volume fraction of carbides. The lowest hardness was observed at the cooling rate at $0.25 \mathrm{~K} / \mathrm{s}$, and may be explained by the low volume fraction and blocky morphology of carbides as well as by the presence of $\gamma / \gamma^{\prime}$ eutectic. At low growth rates, characterized by the cellular solidification front, the carbon and carbide forming elements accumulate at the bottom of the mushy zone, which solidifies very slowly, so the carbides formed are large and have equilibrium faceted morphology. On the other hand, the presence of the $\gamma-\gamma^{\prime}$ eutectic further decreased the hardness. This is because of lower strength and higher ductility of the eutectic phase than the dendrite cores. It has been shown earlier that the room temperature yield strength decreases and the elongation-to-failure increases with the volume fraction of $\gamma-\gamma^{\prime}$ eutectic [18].

As the cooling rate increases, the diffusion time decreases, reducing the time for carbide growth. Also, when the secondary dendrite arms are developed, the inter-secondary dendrite arm region becomes the preferred site for carbide nuclei growth as the carbide forming elements segregate to these regions. It occurs because the concave solid-liquid interface geometry makes outward diffusion of the carbide forming elements difficult. Therefore, the hardness at the cooling rate of $1 \mathrm{~K} / \mathrm{s}$ was higher due to the finer carbides morphology and to the absence of $\gamma / \gamma^{\prime}$ eutectic.
The highest volume fraction of carbides and also the finest structure were found at 5 and $10 \mathrm{~K} / \mathrm{s}$. Moreover, a fine $\gamma / \mathrm{MC}$ eutectic was observed in the inter-dendritic region, as discussed above. This dual carbide distribution led to the highest microhardness.

\section{Conclusions}

The effect of cooling rate on the microstructure of MAR-M247 Nibased superalloy was studied experimentally via physical simulation of the casting process. Based on the experimental results, the following conclusions may be drawn:

- Melting/solidification experiments for cooling rates in the range $0.25-10 \mathrm{~K} / \mathrm{s}$ were successfully performed in the Gleeble thermomechanical simulator.

- temperature profiles were smooth and minor instabilities were only presented at the highest cooling rate of $10 \mathrm{~K} / \mathrm{s}$ but they did not affect the overall cooling rate;

- MAR-M247 showed cellular $(0.25 \mathrm{~K} / \mathrm{s})$ and dendritic $(1,5$ and $10 \mathrm{~K} / \mathrm{s})$ microstructures, respectively. Microconstituents varied with cooling rates: $\gamma / \gamma^{\prime}$ matrix with carbides and $\gamma / \gamma^{\prime}$ eutectic at $0.25 \mathrm{~K} / \mathrm{s}$,

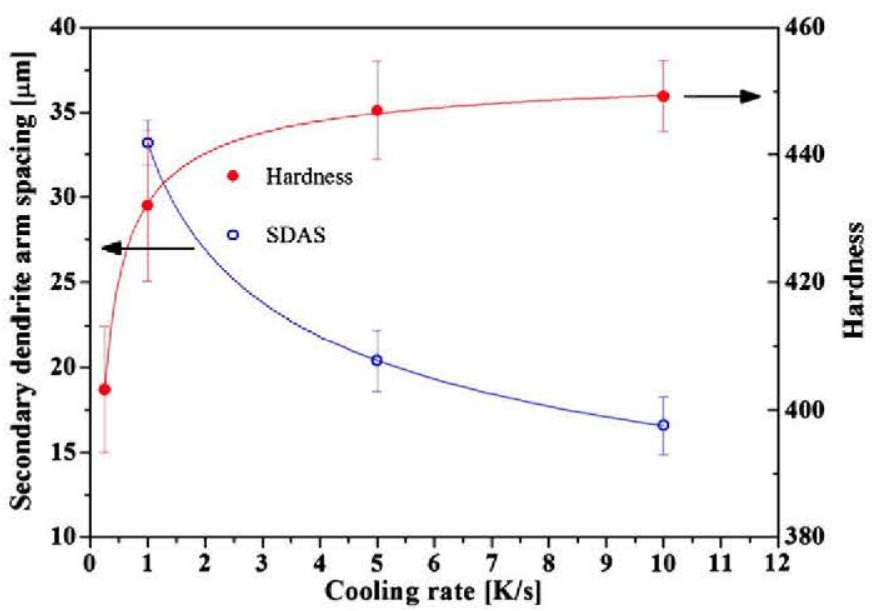

Fig. 3. Secondary dendrite arm spacing (SDAS) and microhardness of the MAR-M247 alloy as a function of the cooling rate. 
$\gamma / \gamma^{\prime}$ matrix with carbides at $1 \mathrm{~K} / \mathrm{s}$ and $\gamma / \gamma^{\prime}$ matrix with carbides and $\gamma / \mathrm{MC}$ eutectic at 5 and $10 \mathrm{~K} / \mathrm{s}$.

- Dendrite spacing decreased and microhardness increased as the cooling rate increased.

\section{Acknowledgments}

This investigation was supported by the project VANCAST (EU, FP7, ERA-NET MATERA+). SM and IS acknowledge the Ramon y Cajal fellowship from the Spanish Ministry of Science and Innovation.

\section{References}

[1] Harris K, Erickson GL, Schwer RE. In: Gell M, Kortovich CS, Bricknell RH, Kent WB, Radvich JF, editors. Superalloys 1984. New York: Metallurgical Society of AIME 1984. p. 221.

[2] Whitesell HS, Li L, Overfelt RA. Influence of solidification variables on the dendrite arm spacings of Ni-based superalloys. Metall Mater Trans B 2000;31:546-51.

[3] Chen J, Lee JH, Jo CY, Choe S], Lee YT. MC carbide formation in directionally solidified MAR-M247 LC superalloy. Mater Sci Eng A 1998;247:113-25.

[4] Whitesell HS, Overfelt RA. Influence of solidification variables on the microstructure, macro segregation, and porosity of directionally solidified MAR-M247. Mater Sci Eng A 2001;318:264-76.

[5] Nathal MV, Ebert L]. The influence of $\mathrm{Co}$, Ta, and $\mathrm{W}$ on the microstructure of single crystal nickel-based superalloys. Metall Mater Trans A 1985;16:1849-62.
[6] Okada M, Tsutsumi M, Kitamura T, Ohtani R. Initiation and growth of small cracks in directionally solidified MAR-M247 under creep-fatigue. Fatigue Fract Eng Mater Struct 1998;21:741-50.

[7] Nathal MV, Maier RD, Ebert LJ. The influence of Co on the microstructure of the Nickel-based superalloy MAR-M247. Metall Mater Trans A 1985;13:1775-83.

[8] Heck K, Blackford JR, Singer RF. Castability of directionally solidified nickel base superalloys. Mater Sci Technol 1999;15:213-20.

[9] Robino CV, Michael JR, Cieslak MJ. Solidification and welding metallurgy of thermo-span alloy. Sci Technol Weld Joining 1997;2:220-30.

[10] Lin CS, Sekhar JA. Solidification morphology and semisolid deformation in superalloy Rene-108 3. Equiaxed solidified microstructures. J Mater Sci 1994;29:3637-42.

[11] Lin CS, Selchar JA. Solidification morphology and semisolid deformation in superalloy Rene-108 4. Directionally solidified microstructures. J Mater Sci 1994:29:5005-13.

[12] Knorovsky GA, Cieslak MJ, Headley TJ, Romig AD, Hammetter WE. Inconel 718: a solidification diagram. Metall Mater Trans A 1989;20:2149-58.

[13] Faes A, Zryd A. Simulations of solidification of Nozzle Guide Vane: preliminary comparison between alloy MAR-M247 and IN718. Internal project report, Sion; April 2011.

[14] Flemmings MC. Solidification processing. Metall Trans A 1974;5:2121-34.

[15] Kurz W, Fisher DJ. Dendrite growth in eutectic alloys: the coupled zone. Int Met Rev 1979;5-6:177-204.

[16] Hellawell A. Growth and structure of eutectics with Si and Ge. Prog Mater Sci $1970 ; 15: 1-78$.

[17] LLorca J, Orera VM. Directionally-solidified eutectic ceramic oxides. Prog Mater Sci 2006;51:711-809.

[18] Gasko KL, Janowski GM, Pletka BJ. The influence of $\gamma / \gamma^{\prime}$ eutectics on the mechanical properties of conventionally cast MAR-M247. Mater Sci Eng A 1988;104:1-8. 